\title{
Resource-saving nanotechnologies in waste water treatment
}

\author{
O.N. Borisova* iD, I.G. Doronkina (D, V.M. Feoktistova ii \\ Russian State University of Tourism and Service, Cherkizovo, Moscow region, Russia \\ * Corresponding author: e-mail: borisova-on@bk.ru
}

\begin{abstract}
This paper examines the prospective field of nanotechnology development in the area of wastewater treatment and water processing. The introduction showed (no need for comma) that the Russian problem is not the lack of water - but its quality. Water treatment is needed to prevent water facilities from pollution. Self-cleaning methods cannot withstand the massive impact of pollutants, some of which are unknown for their natural reproduction processes. The degree of purification depends on the concentration of the pollution and the content of different substances within it. The use of nanotechnologies in effluent neutralization (EN) processes will allow removing insoluble sludges, wastes of chemical industry, and harmful microorganisms. Methods and materials. This work presently uses analytical methods to study nanotechnologies. Nanofiltration and membrane methods are frequently used in wastewater treatment. Methods such as arc charge, ablation, and gas-phase deposition are applied to obtain carbon nanotubes. Results. The authors describe promising carbon nanomaterials for production of membranes used in purification/decontamination/ desalination of water. The new generation of membranes for filtering, disinfection, and desalination have been shown. These include graphene and carbon nanotubes which present absolutely new nanomaterial. Discussion. It was revealed that such membranes are characterized not only by a high water percolation rate, but also by extraordinary selectivity. Such membranes are particularly promising in the field of biomedicine, as large membranes are necessary for the nanofiltration and desalination processes. Conclusions. This paper examines new ecological and resource-saving technologies making possible improved research, industrial and commercial activities (which by means of practical implementation of inventions will lead to improved products), technologies and organizational decisions. One of the most promising areas for the development of nanotechnologies applied in waste water treatment is the advancement of membrane technology employing innovative materials, specifically graphene and carbon nanotubes.
\end{abstract}

KEYWORDS: wastewater treatment, nanofiltration, technology, nanomembranes, graphene, carbon nanotubes.

FOR CITATION: Borisova O.N., Doronkina I.G., Feoktistova V.M. Resource-saving nanotechnologies in waste water treatment. Nanotechnologies in Construction. 2021; 13(2): 124-130. Available from: doi: 10.15828/2075-8545-2021-13-2-124-130.

\section{INTRODUCTION}

$\mathrm{O}$ ne of the most important global goals is to provide the inhabitants of our planet with drinking water of high quality.

Water is the most widespread substance in nature (the hydrosphere occupies $71 \%$ of the Earth's surface). The absence of water makes the existence of microorganisms impossible. The Earth's freshwater plays a special role, and its total volume is not large - just $2.5 \%$ of the ocean's water mass (approximately 30 billion $\mathrm{km}^{3}$ ). Earth's largest freshwater resource is in Baikal lake - which is approximately 23 thousand $\mathrm{km}^{3}$. The vast majority of freshwater is hard-to-reach for people in daily life due to it being frozen and in the underground water-bearing stratum. Therefore, it should be an urgent task to prevent the pollution of the bodies of water which are the sources of fresh water [1].

People actively consume water after it has been treated and processed in numerous activities: at home, in industrial and agricultural production, in some special industries (the food industry, the production of semiconductors and luminophores, and nuclear technologies) as well as for medical treatment, chemical analyses, etc.

The world's technological progresses, which are reliant on the use of natural resources as raw materials, and on the development of the technosphere within the area occupied by cities and towns having proper infrastructure. This has predictably led to ecologically dangerous conditions for human existence. This has occurred due to the production and accumulation of large amounts of waste,

(c) Borisova O.N., Doronkina I.G., Feoktistova V.M., 2021 
the negative impact on the environment of industrial and household activities due to exhausted natural resources mainly freshwater.

\section{METHODS AND MATERIALS}

About half of consumed water turns into wastewater which after being treated is discharged into water reservoirs.

Effluents (Ef) are waters used in industrial or technological processes, and are polluted with different substances as well as sewage (atmospheric) waters, harmful material released into the atmosphere in the form of industrial emissions, and return to the Earth as rainfall which pollute bodies of water and soil [2, 3].

Residential wastewater is removed by the sewage system into waste treatment plants. Rainwater gets into other sewage systems and after mechanical treatment is discharged into surface water bodies. Purified effluents from small industrial plants (car washes, electrodepositions, etc.) can also flow into the stormwater sewage system. After extensive purification, landfills with water treatment waste produced by large-scale industrial plants can also be discharged into bodies of surface water [4].

In fact, due to the negative environmental impact of pollutants which are discharged in the air, and the discharge of containments into bodies of water, the penetration of toxic effluents (which form on solid waste landfills) into water used on soil, watershed areas, and bodies of water (surface and underground) become intensively polluted. Hence, the task of great importance is to provide improved quality control for water in rivers and water reservoirs, and at the same time to design up-to-date wastewater treatment facilities, which use modern wastewater treatment technology [5].

The Russian problem is not the lack of water, but its quality. Water in almost all cities (there are more than a thousand cities in Russia) is supplied not from water from wells but from the surface drainage system. About $75 \%$ of apartments in cities consume water of low quality. And, it is not unlikely, that dangerous microorganisms - as well as toxic substances which are widely used in industry - inevitably get into water pipes and then into the water supply system. A typical city wastewater treatment plant cannot neutralize such effluents. Approximately $30 \%$ of Russia's population consumes water without any treatment, and that is especially dangerous for health. No more than $10 \%$ of the water is purified in Russian regions such as Belgorod and Kursk, Adygea, Buryatia and Tyva.

Russia's management of its water supply is dramatically behind that of EU countries. According to legislation of the Russian Federation, water must be tested by 54 criteria for purity. In most regions - due to the lack of equipment - this requirement is not met. One can compare that with Great Britain where drinking water must meet (or pass) 70 criteria for purity, and additionally one hundred thousand additional tests are typically performed. In Britain the percentage of drinking water inspections which do not meet requirements is a mere $.01 \%$, whereas in Russia more than $40 \%$ of drinking water fails prescribed criteria for purity. That indicates a high percentage of drinking water is not safe for consumption. For example, test results of the water in the Volga river show the water is in the third (the lowest) class for purification. Water treatment facilities in most cities in Volga take water from the river and are required to meet criteria in the first class - the highest one. However, in water purity tests the presence of phenol, oil products, copper and zinc salts in Volga water exceeds the maximum allowable concentration 5-12 times [7].

Typically, countries in the EU apply UF-technologies to treat and purify water, Russia uses mainly chlorum to purify water (the Rublev water station in Moscow employs ozon).

According to WHO's data, $\$ 1$ dollar invested in the maintenance of clean drinking water can save from $\$ 4$ to $\$ 12$ dollars in the healthcare system.

Currently, the number of landfills in Russia which are purified does not exceed $65 \%$. Therefore, it is of great importance to provide engineering that assures the protection of the environment, specifically, to solve the technological task of water conditioning and purification, to recycle the water supply, and to prevent the pollution of bodies of water and to minimize desiccation. Effluent purification is an integral part of ecological engineering, ecosystem services and environmental objects under protection [8-13].

Water purification is needed to prevent the pollution of major water resources. The natural cleansing-process which occurs in nature cannot withstand massive impacts of pollutants, and some of them are unknown for natural reproduction processes. The degree of purification of water depends on the concentration of pollution and the type of substances it contains. The use of nanotechnologies in the effluent neutralization (EN) processes will allow removing insoluble sludges, wastes of chemical industry and harmful microorganisms [12-14].

The terms "nanofiltration" and "nanofiltration membrane" appeared only in the late $1980^{\text {s }}$ due to rapid development of nanotechnologies. Typically, it is assumed that effective size of pores of a nanofiltration membrane is several nanometers, though this range sometimes is widened up to 100 nanometers (nanotechnological objects are commonly considered to have at least one dimension less than 100 nanometers). These membranes are in the middle position between ultrafiltration and reverse osmosis from the point of view of purification degree: they do not pass most part of organic molecules, almost all viruses and two (or more) valency ions. All three types of films work at nano-level. Thus, one can say, nanotechnolo- 
gies had been used for water purification long before the term appeared. Now application of these membranes is spreading in Russia and other countries. In Switzerland, for example, plants of ultrafiltration, nanofiltration and reverse osmosis provide citizens with drinking water from lakes and karst subsoil water [15].

Nanofiltration and membrane methods are increasingly used to purify water. Membrane methods to separate liquid (and gas) mixtures are based on the application of a semipermeable membrane of molecule sizes (thickness is not more than 100 nanometers) with selective permeability. Semi-permeability is the characteristic of the most tissues of microorganisms.

Nanotechnology is defined as a set of methods and tools which provide controlled creation of the objects comprising elements with sizes less than $100 \mathrm{~nm}$ (at least in one dimension) and, as a result of this, attaining completely new properties. The studies performed in many laboratories around the world show that such properties of synthesized materials as large specific area, high permeability, catalytic activity, resistance to biofouling, functionalization ability et al. make it possible to use them for obtaining pure water.

Silver nanoparticles are used to decontaminate drinking water and to decrease biofouling of membranes. Nano- $\mathrm{TiO}_{2}$ is characterized by high photocatalytic activity, and industrial products for clearing water from organic admixtures have been designed on the basis of it.

To control quality of water, the detectors employing magnetic, optic and electric properties of nanoparticles (nano-Au,- $\mathrm{SiO}_{2},-\mathrm{CdSe}$ et al.) and nanocomposites (there are commercial products) are offered. All these nanomaterials cannot be considered in one paper. This paper deals with two allotropic modifications of carbon nanotubes and graphene, which are promising for a new generation of filters and the creation of membranes and filters possessing completely new properties.

A new generation of membranes used for filtration, disinfection and desalination is made on the base of graphene and carbon nanotubes which are characterized by a high coefficient of water permeability, excellent selectivity, resistance to biofouling and strong antibacterial properties [16]. So far only a small percentage of such membranes and filters are being tested around the world, but their commercialization is highly likely to be launched due to the explosive growth of graphene production.

Graphene is a two-dimensional crystal consisting of one layer of carbon atoms. It can be presented in the form of a graphite plane surface, separated from crystal. Carbon nanotubes (CNT) are jointless cylinders from one or several graphene layers, which the diameter is from $.7 \mathrm{~nm}$ to $100 \mathrm{~nm}$ and the length is up to several centimeters with open or closed ends (fig. 1).

It is considered, for the first-time carbon nanotubes were discovered and described in the early $1990^{\text {s }}$ [17]. Soon, unique electric, mechanic, optic and other properties of carbon nanotubes were demonstrated. They were quite promptly applied in practice. The production volume of CNT grew at least 10 times within the years 2006-2012 [18]. CNT in the form of films, coatings, as well as a part of composites are used in microelectronics, automobile, aerospace and military industries, in production of special clothes, sport equipment and medicine articles. According to specialists' forecast, a new exciting area of application is water purification. Experts of RUSNANO's project attempted to apply nanotechnologies in wastewater treatment, regard nanotubes as a prospective material [19].

Today there are the following methods to produce carbon nanotubes: arc charge, ablation and gas-phase deposition.

Arc charge: obtaining (carbon nanotubes are described in the present paper) electric charge in plasma which burns with helium. This process can be performed with the use of special technical equipment for fullerene production. However, this method also employs other modes of arc burning. Burning. For example, current density is decreased and cathodes with great thickness are used. To provide a helium atmosphere it is necessary to increase the pressure of this chemical element. Carbon nanotubes are obtained by spraying. To increase their numbers, a catalyst is needed to be introduced into
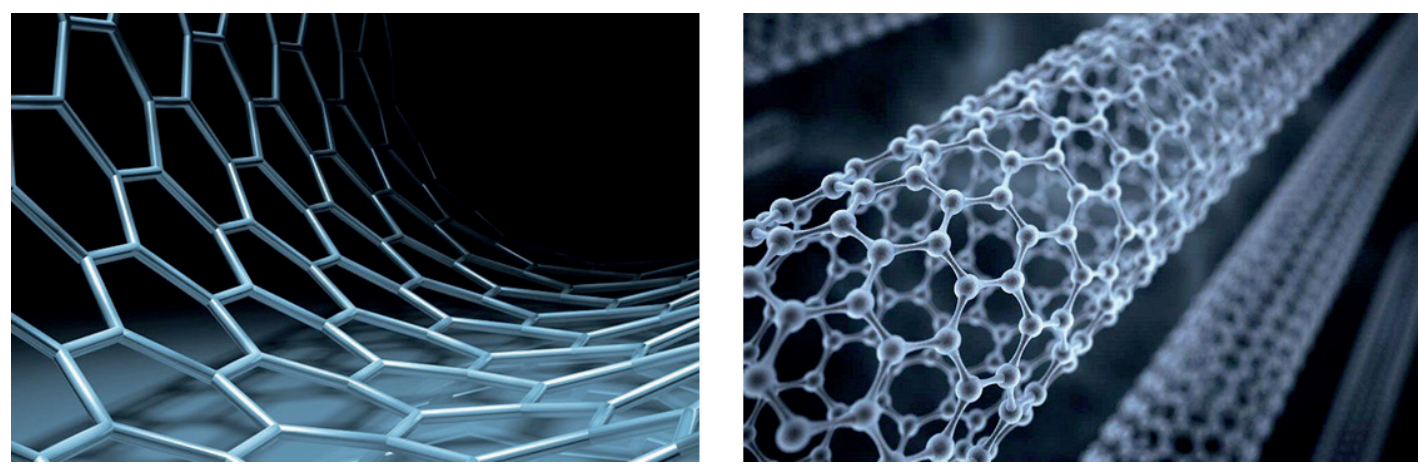

Fig. 1. Graphene, carbon nanotube 
a graphite core. Quite often this is a mixture of different groups of metals. Then the pressure and spraying method are changed. That results in a cathode deposit in which carbon nanotubes are formed. They grow perpendicular to the cathode and bunch. Their length is 40 microns.

Ablation was invented by Richard Smalley. The main idea is that different graphite surfaces vaporize in a reactor working under high temperatures. Carbon nanotubes are formed as a result of graphite vaporizing in the bottom of reactor.

They are cooled and collected with the use of a cooling surface. In the first case, the amount of elements was $60 \%$, in this method this indicator increased by $10 \%$. The Laser method is the most expensive, as it is the most efficient one. As a rule, one-layer nanotubes are obtained due to reaction temperature change.

Vapor-phase deposition. The Carbon vapor deposition method was invented in the late 50s. No one could have expected that it would be used in production of carbon nanotubes. The first step is to prepare the surface with a catalyst. The catalyst can be fine particles of different metals, for example, cobalt, nickel and other. Nanotubes appear from the catalyst layer. Their thickness directly depends on the size of the catalyzing metal. The surface is heated to high temperatures and then gas (methane, acetylene, ethanol et al.) with carbon is supplied. Ammonia is used as an additional technical gas. This method to produce nanotubes is the most widespread. The process runs at different industrial plants, so to produce a large number of tubes requires less expense. Another advantage of this method is that vertical elements can be obtained from any metal particles which are catalysts. Production (carbon nanotubes are described in details) became possible due to research by Sumio Iijima who studied using a microscope their appearance caused by carbon synthesis.

Membranes consisting of straight, open, vertical nanotubes in a dense matrix allow using unique transport properties of these carbon nanomaterials.

As a rule, nanotubes are grown on the base layer, for example, by means of chemical vapor deposition (CVP) method, then the gaps between them are filled in such a way to make water flow to pass only along the channels of nanotubes. Sometimes CNT are synthesized in macro pores of base layers (for example, of aluminum oxide). Self-assembly approaches are used too.

According to authors' estimations [20], membranes with $.03 \%$ nanotubes in a dense matrix can be more efficient than all available reverse osmose systems for sea water desalination. Solvated ions which are larger than inner diameter of nanotube remain in sea water. Passing of finer ions can be stopped by functionalization of CNT. For example, membranes of nanotubes with diameter about $2 \mathrm{~nm}$ in silica nitride synthesized by authors [21] owing to functionalization of CNT did not pass $91 \%$ of ions with a size $.95 \mathrm{~nm}$ when filtering. Calculations of molecular dynamics prove efficiency of CNT usage in sea water desalination [22].

\section{RESULTS}

Promising carbon nanomaterial for the creation of membranes for purification/decontamination/desalination of water is the use of graphene and carbon nanotubes. These elements are completely new representatives of nanomaterials. They possess frame structures which differ from graphite or diamond by their characteristics. That is why they are used much more often than other materials.

For many years researchers have been using carbon nanotubes where application is not limited only by one area. The market position of this material is weak as there are some problems concerning large-scale production. Another important issue is a high cost of CNT which is about $\$ 120$ dollars for 1 gram.

Graphene membranes and filters can be used in wastewater treatment in all stages: from drawing of water from natural sources to the places where it will be consumed or used. These are new generation of membranes for filtration, disinfection, desalination. Very low resistance is possible when water passes through nanotubes, and capillary-like effect in graphene reduces resource and energy-consumption. Membranes are resistant to biofouling, and they possess antibacterial properties which can be increased by the functionalization of $\mathrm{Ag}$ or $\mathrm{TiO}_{2}$ nanoparticles or antibiotics. Functionalization with CNT makes it possible to create analogues of aquaporin "water channels". Due to high rate of water penetration in combination with extra selectivity graphene membranes can efficiently derive freshwater from the sea.

Today only a small part of graphene membranes and filters are being studied in pilot tests. Scarce information on commercial use is available. The filters Seldon Nanomesh TM is an exception. According to its manufacturers, filtration material consists of carbon nanotubes, absorbent coal and fibers. Filters remove $99.999 \%$ of bacteria, 99.99\% of viruses, colourants, lead and cadmium, pesticides and herbicides, Ce137 etc. They are applied in water purification processes in dwelling blocks and in portable devices used in army or humanitarian aid.

\section{DISCUSSION}

As it is known, in the 2004 future Nobel Prize Laureates Andre Geim and Konstantin Novoselov obtained innovative material, having separated layers from regular graphite by means of a tape. They were awarded with the Nobel Prize in Physics in 2010 "for advanced experiments with two-dimensional material - graphene." By that time many laboratories all around the world had received the results which indicated particular electronic, optic, me- 
chanical, thermal and other properties of graphene. Recently unique membranes on the basis of graphene have been produced.

The authors of [23] created pores with $.4 \mathrm{~nm}$ diameter (void density is $1012 / \mathrm{cm}^{2}$ ) in graphene by means of ion bombardment method and further etching process, they were the first who demonstrated selectively fast transfer of ion in one atom membrane. Permeability is 50 times more than that of regular membranes used in water desalination. The authors consider their membrane are particularly promising for biomedicine use as big membranes are needed in nanofiltration or desalination processes. The scaling problem can be solved by applying so-called graphene oxide instead of graphene which can be easily obtained as a result of the delamination of preoxygenated graphite into separate layers.

The authors of [24] created a membrane with one micron thickness. It consists of layers of graphene oxide interconnected in the way similar to the multilayer structure in mother-of-pearl. Such membrane is impermeable for all gas, vapours and liquids, but water easily passes through it.

The researchers explain that as a result is the formation of the graphene nanocapillary grid in the graphene oxide layers. Diffusion of many molecules is blocked by the reduction of capillaries under low moisture and/or by filling them with water. The new work [25] shows that such a membrane is characterized not only by a high rate of water penetration but also by extraordinary selectivity. Hydrated ions with radiuses more than $.45 \mathrm{~nm}$ cannot pass through it, and smaller ions are efficiently captured into capillaries (according to authors' data [26-28], phenomena take place if the pressure on the ion is $>50 \mathrm{~atm}$ ). A challenge for future research is to decrease the size of capillaries in order to use such membranes in the desalination of sea water.

\section{CONCLUSION}

Carbon nanotubes play an important role in innovative technologies. Many experts predict growth of this area in the near future. Dramatic increase of productive capacities will cause a decrease of product prime cost. Having dropped in price, demand for nanotubes will increase, and that will make them an indispensable material for many devices and equipment.

Unfortunately, one should admit, despite notable Russian scientific achievements, production of grapheme, CNT and new materials based on them is restricted, and it is too early to speak about implementation of membranes of a new generation.

The reasons for slow progress are the technical obstacles, and high cost for manufacturing. But these are temporary problems. One need merely to remember the history of the development of polymer membranes, which first laboratory samples were obtained in our country about 50 years ago. Within several years, the assortment of membrane and membrane elements was widened, and purposeful cooperation between researchers, technologists and government bodies launched rapid development of membrane technologies. Hopefully, membrane technologies will keep the same scenario. At this, one shouldn't forget important issues concerning the safety of application of nanomaterials. Certainly, the probability that - when using membranes - carbon nanotubes or graphene nanoplates will get into environment is rather low. But this may happen in the production process, recycling, transportation or utilization. It is necessary to use unique characteristics of synthesized materials to avoid possible toxic effects.

Development of new ecological resource-saving technologies will lead to improved research, production and commercial activities, when implemented in practice results in the appearance of better products, technologies and organizational solutions. One of the most promising areas for development of nanotechnologies concerning water treatment and water conditioning is membrane technology with innovative materials. Expansion in the application of nanotechnology in this area will inevitably will lead to increased content of nanomaterials in Russia's vast and critical water resources. Therefore, the development of analytical methods aimed at determination of nanoparticles becomes a separate issue. Methods proposed today are complex, too expensive and restricted.

\section{REFERENCES}

1. Borisova O. Classification of waste water by different criteria and the methods of waste water treatment. Waste water treatment. 2019;3:57-61.

2. Shubov L.Ya., Borisova O.N., Doronkina I.G. Technology of waste water treatment. Control of environment quality. Educational book for discipline "Engineering protection of environment in management of wastes from production and consumation”. Moscow, 2013. 
3. Shubov L.Ya., Borisova O.N., Doronkina I.G. Technologies of waste water treatment. (engineering protection of hydrosphere). Scientific and Engineering Aspects of Environmental Protection. 2010;6:2-128.

4. Shubov L.Ya., Borisova O.N., Doronkina I.G. Increasing of ecoefficiency of waste water treatment technology. Waste water treatment. 2016;11:26-32.

5. Doronkina I.G., Borisova O.N. Ecological and economic efficiency of technological processes of wastewater treatment. Service in Russia and Abroad. 2015;4:112-12.

6. Shubov L.Ya., Borisova O.N., Doronkina I.G. On Improving the Eco-Efficiency of Wastewater Treatment Technologies. Service in Russia and Abroad. 2014;1:153-162.

7. Doronkina I.G., Borisova O.N. Waste water treatment in a modern city. Slavic Forum. 2020; 2: 146-158.

8. Shaytura S.V. Hybrid systems. In: Shaytura S.V. Intelligent systems and technologies. Burgas: Institute of Humanitarian Sciences, Economics and Information Technologies; 2016. p. 63-82.

9. Shaytura S.V. Mission is possible. Slavic Forum. 2012;1(1);47-52.

10. Shaytura S.V. Neural networks. In: Shaytura S.V. Intelligent systems and technologies. Burgas: Institute of Humanitarian Sciences, Economics and Information Technologies; 2016. p. 47-62.

11. Shaytura S.V. Nature protection technologies - the basis of the seventh technological paradigm. Design Bureau. 2017;3(128);12 - 14.

12. Kremena Stereva, Shaytura S.V. Using The Terrestrial Laser Scanning Technology For Detection Of Cracks In Rock Massifs. Slavic Forum. 2021;1(31):241-247.

13. Stereva Kremena, Postolovski A., Shaytura S.V. Using Mobile Laser Scanning In Road Safety Repair And Audit. Slavic Forum. 2021;1(31):248-257.

14. Bokareva E.V., Silaeva A.A., Borisova O.N., Doronkina I.G., Sokolova A.P. Analysis of the world and russian e-commerce market: development trends and challenges. International Journal of Engineering and Technology(UAE). 2018;7(4.38):387-392.

15. Borisova O.N., Silayeva A.A., Saburova L.N., Belokhvostova N.V., Sokolova A.P. Talent management as an essential element in a corporate personnel development strategy. Academy of Strategic Management Journal. 2017;16(S1):31-46.

16. Doronkina I.G., Borisova O.N. Ion-exchanged technologies of waste water treatment with the use of ionites. In: Science, education, production for solution of ecological problems. (Ecology-2020): Proceedings of the XVI International Scientific and Technical Conference, in 2 volumes, devoted to $75^{\text {th }}$ Anniversary of the Victory in Greate Patriotic War. Ufa; 2020. p. 291-296.

17. Ivanov L.A., Borisova O.N., Muminova S.R. The inventions in nanotechnologies as practical solutions. Part I. Nanotechnologies in Construction. 2019; 11(1): 91-101. Available from: doi: 10.15828/2075-8545-2019-11-1-91-101.

18. Ivanov L.A., Kapustin I.A., Borisova O.N., Pisarenko Zh.V. Nanotechnologies: a review of inventions and utility models. Part II. Nanotechnologies in Construction. 2020;12(2):71-76. Available from: doi: 10.15828/2075-85452020-12-2-71-76.

19. Baumgartner H. Nanopores for clean drinking water. Environment. Nanotechnology. 2010;3:18-20.

20. Svitsov A.A. Membrane technologies in Russia. The Chemical Journal. 2010; 10: $22-24$.

21. De Volder M.F.L., Tawfick S.H., Baughman R.H., Hart A.J. Carbon nanotubes: present and future commercial applications. Science. 2013;339:535-539.

22. Vigdorovich V.I., Mischenko S.V., Tkachev A.G. Nanostructured materials and technologies. State-of-art, problems and prospectives. Transactions TSTU. 2007;13(4):983.

23. Pendergast MT. M., Hoek E. M.V. Review of water treatment membrane nanotechnologies. Energy \& Environmental Science. 2011;4:1946-1971.

24. Fornasiero F., Park H.G., Holt J.K., Stadermann M., Grigoropoulos C.P., Noy A. and Bakajin O. Ion exclusion by sub-2-nm carbon nanotube pores. P. Natl. Acad. Sci. USA. 2008;105:17250-17255.

25. Corry B. Water and ion transport through functionalised carbon nanotubes: applications for desalination technology. Energy Environ. Sci. 2011;4:751-759.

26. O’Hern S.C., Boutilier M.S., Idrobo J.-C., Song Y., Kong J., Laoui T., Atieh M., Karnik R. Selective ionic transport through tunable subnanometer pores in singllayer graphene membranes. Nano Lett. 2014;14:1234-1241.

27. Nair R.R., Wu H.A., Jayaram P.N., Grigorieva I.V., Geim A.K. Unimpeded permeation of water through helium-leak-tight graphene-based membranes. Science. 2012;335:442-444.

28. Joshi R.K., Carbone P., Wang F.C., Kravets V.G., Su Y., Grigorieva I.V., Wu H.A., Geim A.K., Nair R.R. Membranes precise and ultrafast molecular sieving through graphene oxide. Science. 2014;343:752-754. 
INFORMATION ABOUT THE AUTHORS

Oksana N. Borisova, Cand.Sci. (Eng.), Assistant Professor, Higher School of Service, Russian State University of Tourism and Service, ORCID: https://orcid.org/0000-0002-7391-6170, e-mail: borisova-on@bk.ru

Irina G. Doronkina, Cand.Sci. (Eng.), Director of Sport Department, Russian State University of Tourism and Service, ORCID: https://orcid.org/ 0000-0001-7354-4293, e-mail: dora1096@yandex.ru

Valentina M. Feoktistova, Cand.Sci. (Eng.), Assistant Professor, Higher School of Service, Russian State University of Tourism and Service, ORCID: https://orcid.org/0000-0001-8880-8941, e-mail: vfeoktistova@gmail.com

\section{Authors declare the absence of any competing interests.}

Received: 04.03.2021.

Revised: 29.03.2021.

Accepted:02.04.2021. 